\title{
Computational fluid dynamics analysis of a three-dimensional electric submerged arc furnace operation
}

\author{
K. Karalis ${ }^{1 *}$, N. Karalis ${ }^{2}$, N. Karkalos ${ }^{3}$, G.S.E. Antipas ${ }^{4}$ and A. Xenidis ${ }^{2}$ \\ ${ }^{1}$ Institute of Geological Sciences, University of Bern, CH-3012 Bern, Switzerland \\ ${ }^{2}$ Mechanical Engineer, Mining and Metallurgical Engineer, National Technical University of \\ Athens, MSc, PhD, Athens, Greece \\ ${ }^{3}$ School of Mechanical Engineering, National Technical University of Athens, Zografou \\ Campus, Athens 15780, Greece \\ ${ }^{4}$ Molecular Modelling Laboratory (MML), Park Innovare, CH-5234 Villigen, Switzerland \\ *Email: konstantinos.karalis@geo.unibe.ch, Tel. +41 (0) 316314564
}

\begin{abstract}
A computational fluid dynamics (CFD) method is proposed for the analysis of the operation of a submerged electric arc furnace (EAF) used in the ferronickel production. The three-dimensional mathematical model was initiated for the time dependent solution of the fluid flow, heat transfer and electromagnetic phenomena. The physical properties of the slag, which has crucial role in the EAF operation were determined using classical molecular dynamics simulations and empirical relationships. The analysis revealed that the main slag properties affecting the EAF operation are the density, viscosity and electrical conductivity the latter two being mutually dependent. The high electrical conductivity values of the slag favors melting via the high Joule heat produced within the slag region. Calculation of the dimensionless Péclet and Reynolds numbers revealed that the slag velocities play a decisive role in heat transfer and further indicate that the slag flow is laminar. The average slag velocity calculated $0.0001 \mathrm{~m} / \mathrm{s}$ with maxima in the vicinity of the electrodes.
\end{abstract}

\section{Keywords}

computational fluid dynamics; submerged-arc electric furnace; Söderberg electrodes; magnetohydrodynamics; Joule heating; Lorentz force; reductive smelting; slag 


\section{Introduction}

The principal ferronickel production route involves reductive roasting of lateritic ores in rotary kilns towards formation of calcine ${ }^{1}$, which further undergoes excess-carbon smelting ${ }^{2}$ in megawatt electric arc furnaces $(\mathrm{EAF})^{3-5}$. EAFs typically operate at temperatures as high as $2000 \mathrm{~K}^{\underline{6}}$ under the effect of Joule heating maintained by a number of self-backing Söderberg electrodes $^{\underline{7}}$ which are continuously consumed via submersion into a slag melt ${ }^{1, \underline{Z}}$. FeNi recovery is, then, achieved by continuous chemical reduction promoted by high-temperature (fast) metal/slag reaction kinetics, enhanced mass and heat transfer, electromagnetic stirring of the slag bath owing to buoyancy effects ${ }^{7, \underline{8}}$ and low slag viscosity $\underline{9}$. Intrinsically, however, metal recovery is dependent on the slag's electrical conductivity (EC) and its effect on transport properties of the mesoscale $\frac{10-12}{}$; slag EC itself is very sensitive to even fractional changes in the chemical concentration of the ore, which reflect on final nickel quality.

Ultimately, slag and ferronickel EC define the association between the chemical composition of the ore feed and the energy consumption of the EAF; this association constitutes the most substantial reductive smelting metric - exclusively determined by trial and error ${ }^{1}-$ and an intrinsically multi-scale modelling problem which has not been addressed so far. To this extent, we previously reported the first step of a multi-scale approach, regarding the first principles' prediction of mesoscale slag EC to within $10 \%$ of the experimentally determined value $(81.1$ $\mathrm{S} / \mathrm{m}$ at $1773 \mathrm{~K}$ ) for an industrial-grade reductive smelting implementation ${ }^{6}$. In the current study, we apply the pre-determined properties (based on the atomic order, atomistic modeling) on the development of a three-dimensional mathematical model in order to examine the effect of the main operational parameters (applied voltage, current density etc.) in the process efficiency. The distribution of temperature, velocity and density in respect to the slag electrical and thermal conductivity was determined. Based on the obtained results, correlations based on the slag composition to the overall power consumption can be made.

\section{Methods}

CFD model formulation. Maxwell's equations were solved throughout the three-dimensional CFD domain to account for heat generation due to the materials' resistance to the flow of electric current (Joule heating). These equations consist of the two Gauss laws, the Faraday law and the Ampere law $\underline{15}$. If the charge density is initially zero, it remains zero at all times 
thereafter. In the absence of free charge density and of an external magnetic field, these equations respectively revert to the following form $\underline{16}$

$$
\begin{gathered}
\boldsymbol{\nabla} \cdot \mathbf{E}=0 \\
\boldsymbol{\nabla} \cdot \mathbf{B}=0 \\
\boldsymbol{\nabla} \times \mathbf{E}=-\frac{\vartheta \boldsymbol{B}}{\vartheta t} \\
\boldsymbol{\nabla} \times \mathbf{B}=\mu_{0} \boldsymbol{j}+\mu_{0} \varepsilon_{0} \frac{\partial \boldsymbol{E}}{\partial t}
\end{gathered}
$$

where $\mathbf{E}(\mathrm{V} / \mathrm{m})$ is the applied (external) electric field, $\mu_{0}(\mathrm{H} / \mathrm{m})$ is the magnetic permeability, $\varepsilon_{0}$ is the permittivity of free space. In the case where $E$ is constant, the term in the right side of Eq. 4, which is describing the displacement current, is vanishing. The magnetic field $\mathbf{B}$ [T] is describing by the equation

$$
\mathbf{B}=\boldsymbol{B}_{\mathbf{0}}+\boldsymbol{b}
$$

where $\mathbf{B}_{\mathbf{0}}$ and $\mathbf{b}$ represent the contributions from the external and induced magnetic field, respectively; in the current model, $\mathbf{B}_{\mathbf{0}}$ is by definition zero and we have previously shown $\mathbf{b}$ to be infinitesimal ${ }^{7,8}$ and may, thus, be ignored. We note that Eq. 4 is valid under the additional provision that charge mobility is sufficiently low.

On the basis of the electric field, the current density field, $\mathbf{j}\left(\mathrm{A} / \mathrm{m}^{2}\right)$, was calculated from the Ohm's law for a fluid with a velocity field $\mathbf{u}(\mathrm{m} / \mathrm{s})$, formally expressed as inside a magnetic field

$$
\mathbf{j}=\sigma(\boldsymbol{E}+\boldsymbol{u} \times \boldsymbol{B})
$$

where $\sigma(\mathrm{S} / \mathrm{m})$ is the electrical conductivity and the term $\mathbf{u} \times \mathbf{B}$ is due to the induced field. The magnetic force (Lorentz force law) in a charge $Q$, moving with velocity $\boldsymbol{u}$ in a magnetic field $B$ is $\frac{17}{}$

$$
F_{m a g}=Q(E+u \times B)
$$


The mathematical statement of electric local charge conservation law can be formulated in the equation of continuity in the form of $\frac{17}{2}$

$$
\frac{\partial \rho}{\partial t}+\boldsymbol{\nabla} \cdot \boldsymbol{j}=\mathbf{0}
$$

where $\rho$ is the volume charge density and $\boldsymbol{J}$ is the volume current density.

In Eq.7, the applied electric field $\mathbf{E}$ is also expressed as the gradient of an electric potential, $\varphi(\mathrm{V})$ by satisfying

$$
\mathbf{E}=-\nabla \varphi
$$

and due to Equations (6)-(8) it arises

$$
\nabla^{2} \varphi=\nabla \cdot(\mathbf{u} \times \mathbf{B})
$$

The velocity field was computed via the momentum differential equations describing the convective motion of a fluid with variable density $\rho(t)$ (the latter required in order to be able to resolve thermal buoyancy effects in the EAF) as $\frac{18}{}$

$$
\frac{\vartheta}{\vartheta t} \rho+\nabla \cdot(\rho \boldsymbol{u})=0
$$

and

$$
\frac{\vartheta}{\vartheta t} \rho \mathbf{u}+\nabla \cdot(\rho \mathbf{u u})=-\nabla \mathrm{P}+\nabla \cdot(\mu \nabla \boldsymbol{u})+\rho g+\mathbf{j} \times \mathbf{B}+\mathrm{S}_{\mathbf{u}}
$$

where, $\mathrm{P}(\mathrm{Pa})$ is the pressure and $\mu(\mathrm{Pa} \cdot \mathrm{s})$ is the dynamic viscosity. In Eq.12, the combined effect of the intensity of the magnetic field and of the current density yields the Lorentz force source $(\mathbf{j} \times \mathbf{B})$, the source term $S_{\mathrm{u}}$ modifies the momentum balance depending on completion of solid-liquid phase change and vice versa by dampening the velocity at the phase change interface (solid-liquid) so that it becomes that of the solidified phase after the transition $\frac{19}{}$ and $\mathrm{g}$ is the gravity force. $\mathrm{S}_{\mathrm{u}}$ is given by $\underline{19, \underline{20}}$

$$
\mathrm{S}_{\mathrm{u}}=\frac{(1-a)^{2}}{a^{3}+\varepsilon} A_{m u s h}\left(\boldsymbol{u}-\boldsymbol{u}_{\boldsymbol{s}}\right)
$$


where $\alpha$ represents the volume fraction of the liquid phase, $\mathrm{A}_{\text {mush }}$ and $\varepsilon$ represent arbitrary constants respectively ( $\mathrm{A}_{\text {mush }}$ should be large and $\varepsilon$ small to produce a proper damping) $\frac{19}{}$ and $\mathbf{u}_{\text {solid }}$ is the velocity of the solidified material $(\mathrm{m} / \mathrm{s})$.

Finally, the EAF temperature field, $\mathbf{T}(\mathrm{K})$, obeys energy conservation $\underline{18}$

$$
\rho C_{p} \frac{\vartheta \mathbf{T}}{\vartheta t}+\left(\rho C_{p} \boldsymbol{u} \cdot \nabla\right) \mathbf{T}=\nabla \cdot(k \nabla \mathbf{T})+\frac{\mathbf{j} \cdot \mathbf{j}}{\sigma}
$$

where, $\rho$ is the fluid density $\left(\mathrm{kg} / \mathrm{m}^{3}\right), \mathrm{C}_{\mathrm{p}}$ is the heat capacity $(\mathrm{J} /(\mathrm{kg} \cdot \mathrm{K})), \mathrm{k}$ is the thermal conductivity $(\mathrm{W} /(\mathrm{m} \cdot \mathrm{K}))$ and $\sigma$ is the electrical conductivity $(\mathrm{S} / \mathrm{m})$. The $\mathbf{j} \cdot \mathbf{j} / \sigma$ term in Eq.14 represents the energy source (Joule heating) ${ }^{21}$, relating the flow of electric current, $q$

$$
q=\frac{j \cdot j}{\sigma}
$$

where $\sigma$ is equal either to the slag's ionic contribution computed via the Nernst-Einstein relationship based on our precursor MD structural modelling (electrical conductivity range between 27 to $233 \mathrm{~S} / \mathrm{m}$ for temperature range of 1473 to $1773 \mathrm{~K}$ ) or set to FeNi literature $\operatorname{value}(s)^{\underline{22}} \underline{23}$.

CFD simulations. Convergence was assumed when the residual of the discretized equations fell below a preset tolerance of $10^{-6}$. The coupled thermal/electromagnetic problem (i.e. the system of Eq.11 to 14) was solved via the stationary direct solver MUMPS ${ }^{24}$. The grid of the EAF model consisted of 3237985 free tetrahedron mesh elements, with the worst element having a minimum quality of 0.7465 ; element quality for the tetrahedron mesh was defined as $\underline{24}$,

$$
\mathrm{q} 1=\frac{72 \sqrt{3} \mathrm{~V}}{\left(\mathrm{~h}_{1}^{2}+\mathrm{h}_{2}^{2}+\mathrm{h}_{3}^{2}+\mathrm{h}_{4}^{2}+\mathrm{h}_{5}^{2}+\mathrm{h}_{6}^{2}\right)^{3 / 2}}
$$

where $\mathrm{V}$ is the volume and $\mathrm{h}_{1}-\mathrm{h}_{6}$ are the side lengths of the tetrahedron. If $\mathrm{q} 1>0.1$ the mesh quality (skewness) is not expected to affect the quality of the solution ${ }^{24}$. All CFD simulations were performed with COMSOL Multiphysics ${ }^{\mathrm{TM}} \underline{21}$.

Materials properties. The air, slag and ferronickel phases were considered as homogeneous fluid continua ${ }^{\underline{7}}$. The density, viscosity and electrical conductivity of the slag layer as well as 
the electrical conductivity of the ferronickel layer were modeled as functions of temperature (see Table 1). For the slag the values obtained by performing MD simulations while for the other domains the properties obtained from the literature $\frac{11,25-32}{}$.

Table 1. Thermophysical properties of materials used in the computations. The slag properties were determined via MD simulations while for the ferronickel, electrode and firebrick domains they were obtained from the literature $\underline{11,25-32}$.

\begin{tabular}{|l|l|l|l|l|}
\hline Properties & Slag & Ferronickel & Electrodes & Firebricks \\
\hline Density $\left[\mathrm{kg} / \mathrm{m}^{3}\right]$ & $\begin{array}{l}7.48 \cdot 10^{-8} \mathrm{~T}^{3}-3.799 \cdot 10- \\
4 \mathrm{~T}^{2}+0.25704 \mathrm{~T}+3294.203\end{array}$ & 7000 & 1800 & 2300 \\
\hline Viscosity $[\mathrm{kg} /(\mathrm{m} \cdot \mathrm{s})]$ & $5 \cdot 10^{13} \cdot \mathrm{T}^{-4.776}$ & 0.005 & - & - \\
\hline Heat capacity $[\mathrm{J} /(\mathrm{kg} \cdot \mathrm{K})]$ & 1700 & 525 & 1800 & 1000 \\
\hline $\begin{array}{l}\text { Thermal conductivity } \\
{[\mathrm{W} /(\mathrm{m} \cdot \mathrm{K})]}\end{array}$ & 1 & 15 & 18 & 1.22 \\
\hline $\begin{array}{l}\text { Electrical conductivity } \\
{[\mathrm{S} / \mathrm{m}]}\end{array}$ & $5.34\left(\mathrm{~T}<\mathrm{T}_{\mathrm{melt}}\right)$ & $1 \mathrm{E} 6-330.83 \mathrm{~T}$ & 25000 & 0.01 \\
\hline Solidus temperature $[\mathrm{K}]$ & $1427.32-0.866 \mathrm{~T}+0.000414 \mathrm{~T}^{2}-$ & & & \\
\hline Liquidus temperature $[\mathrm{K}]$ & 1450 & 1570 & - & - \\
\hline Latent heat $[\mathrm{J} / \mathrm{kg}]$ & 400000 & 1600 & - & - \\
\hline
\end{tabular}

\section{Results and Discussion}

By solving the equations (12)-(15) the values and the corresponding gradients of temperature and velocity were calculated in the developed three dimensional discretized domain. The temperature gradients in the EAF are a direct outcome of Joule heating 22 which, in turn, is proportional to the current density, $\mathrm{j}$, relating the flow of electric current, $\mathrm{q}$ according to equation (14) $)^{\underline{7}, \underline{8}}$. To calculate $\mathrm{j}$, the aggregate FeNi/slag $\sigma$ value can be inputted into Eq.5, then solving the system of Eq.5 and 10 in order to obtain the spatial distribution of the electric potential $\mathrm{V}$, on the provisions that $\mathrm{B}$ is zero as there is no magnetic field external to the EAF rig, $\mathrm{B}_{0}$ is by definition zero (Eq.6) and $\mathrm{b}$ is negligible as previously shown by $\mathrm{us}^{\underline{8}}$. In this manner we were able to examine whether the experimentally-observed electric EAF potential in the 
range 380-400 V may be reproduced by setting the applied electric current of the CFD model to values within the EAF operating parameter range of 68-72 kA.

Hence, alternating current with a frequency of $5 \mathrm{~Hz}$ and a maximum potential of $380 \mathrm{~V}$ was applied to the upper surface of the electrodes $(V=380 \cdot \sin (\omega t+\varphi)$, $\varphi$ equal to 0,120 and 240 respectively for each electrode, Fig.1). On the furnace freeboard, immediately above the air

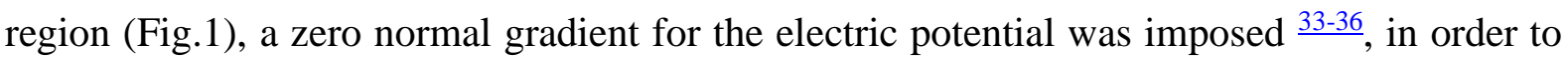
maintain the current densities and the joule heating phenomenon. In the firebrick-lined side walls adjacent to the air and slag layers, a constant heat-transfer coefficient of $100 \mathrm{~W} /\left(\mathrm{m}^{2} \cdot \mathrm{K}\right)$ and a free-stream temperature of $293.15 \mathrm{~K}$ were $\operatorname{set}^{\frac{33}{3}}$, equaling that of the water-cooled firebricks. In the firebrick side walls adjacent to the ferronickel layer, the temperature was set equal to that if the free stream and a constant heat-transfer rate of $10 \mathrm{~W} /\left(\mathrm{m}^{2} \cdot \mathrm{K}\right)$ was used, in accordance with the physically sensible value proposed in the literature $\underline{33}, \underline{34}$. At the bottom of the furnace the temperature was considered to be constant and equal to $313.15 \mathrm{~K}$ (based on measurements performed at the Larco plant) and the heat transfer-coefficient was set to $2 \mathrm{~W} /\left(\mathrm{m}^{2} \cdot \mathrm{K}\right)$. Since the flow was treated exclusively within the region containing the slag, noslip conditions $(\mathrm{u}=\mathrm{v}=0)$ needed to be imposed at the interfacial boundaries between both the slag and electrodes and the ferronickel and firebricks, while a slip boundary condition $(\mathrm{v}=0)$ was imposed on the slag and air interfaces $\stackrel{34-37}{ }$. We note here that slip conditions ought to be applied in cases where viscous effects are negligible and there is no boundary layer, such as in a fluid/solid interface. As we determined previously $\underline{\underline{8}}$ the no-slip condition is particularly suitable for the interaction with a solid wall, when liquid layers adhere to a nearby solid boundary, due to infinite shear stress which reduces which velocity to zero, whereas slip boundary conditions are related to a stress-free condition in the gas-liquid interface.

Distribution of Electric Potential. In order to understand the electric and thermal phenomena inside the EAF we calculated the distribution of electric potential as portrayed in Fig.1a on the time frame of $0.02 \mathrm{~s}$ across three cross sections. In the current frame the three electrodes are under potential values of $-330 \mathrm{~V}, 330 \mathrm{~V}$ and $0 \mathrm{~V}$ respectively. Due to the ground potential applied in the sidewalls, the potential distribution inside the EAF lies between a minimum value of $0 \mathrm{~V}$ and a minimum/maximum of $-380 \mathrm{~V}$ and $380 \mathrm{~V}$ respectively. It is evident that the vast majority of the EAF's sub-regions are under virtually zero electric potential, with the mere exception of regions in the immediate vicinity (up to $2.5 \mathrm{~m}$ ) of electrode edges, which are affected by the applied potential in the three electrodes. This observation is on a par with very 
similar behavior observed based on our own precursor 2D analysis of the same EAF layout, having applied direct current (DC $)^{7, \underline{8}}$. Consequently, a qualitative agreement of electric potential distribution behavior is observed between 2D and 3D simulations.

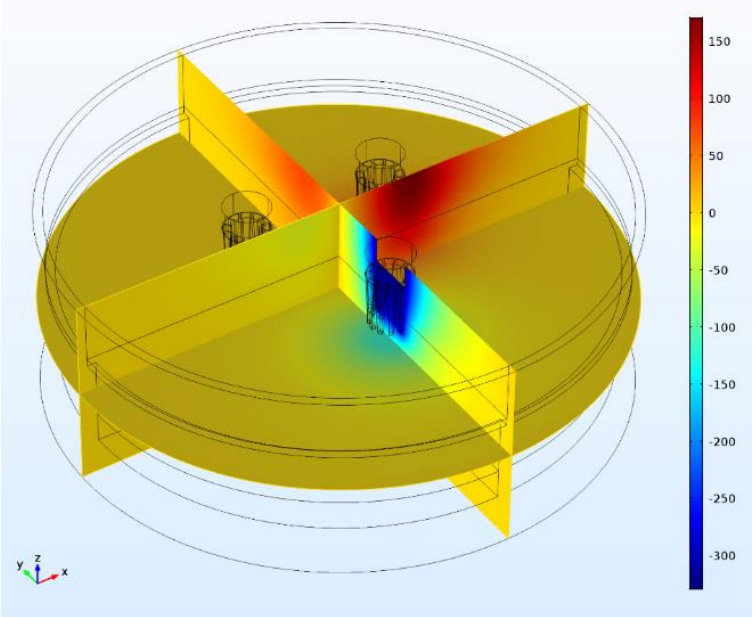

(a)

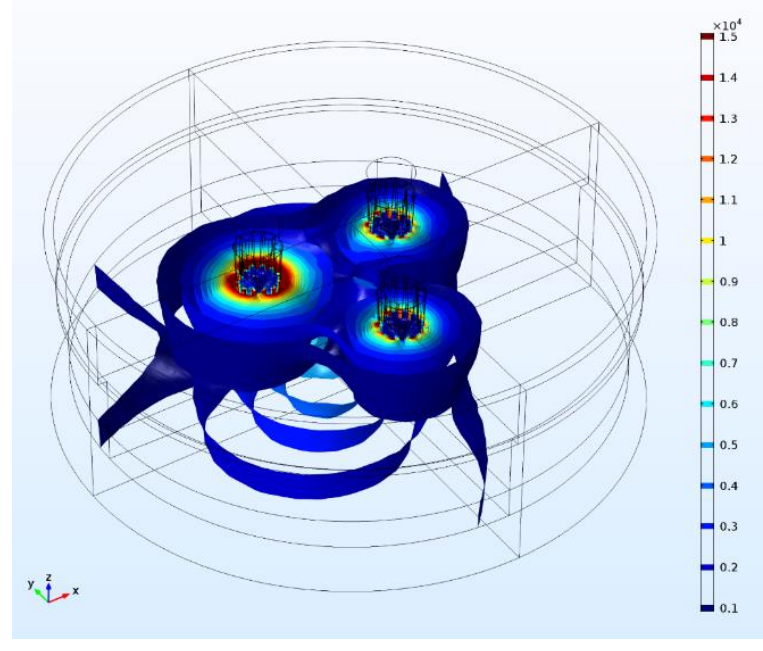

(b)

Figure 1. a) Electric potential distribution (V) in the EAF extracted from a frame at $0.02 \mathrm{~s}$. The minimum and maximum electric potential values are detected within the electrode core and a strong decay to ground values $(0 \mathrm{~V})$ is observed and b) Current density isosurfaces at the time frame of $0.015 \mathrm{~s}$. In comparison to the electric potential values, the current density is observed in both slag and ferronickel regions.

Based on the previous findings, and in order to understand the effect of the melting on the distribution of electric potential we decided to investigate the evolution for the computational time steps of $0,2500,7500$ and $10000 \mathrm{~s}$ across an intercept line from $\mathrm{x}_{1}=0$ to $\mathrm{x}_{2}=17 \mathrm{~m}$ for constant $y=1.7 \mathrm{~m}$. The line chosen was $20 \mathrm{~cm}$ lower than the electrode tips in order to avoid spurious effects in the electrode corners (and to achieve smoother distribution, see Fig.2). Along the intercept, we were able to observe physically meaningful electric potential variations with respect to the selected timesteps owing to the $5 \mathrm{~Hz}$ alternating current and to the temperature dependence of the electrical conductivity of the slag. In the later time steps (e.g. $5000 \mathrm{~s}$ ) the electrical potential drop is smoother, which is due to the higher electrical conductivity values of the slag (cross-related to slag temperature). Aiming to determine the electric potential drop in respect to temperature, we focused our study on timesteps of $0 \mathrm{~s}$ and $2500 \mathrm{~s}$, for which we observed a potential drop equal to $35-40 \%$ at distances of $50 \mathrm{~cm}$ from the electrode edge, while for $10000 \mathrm{~s}$ the same pressure drop was determined to lie approximately $2.3 \mathrm{~m}$ from the electrode edge. Confirming model integrity, for timesteps of $5000 \mathrm{~s}$ and 7000 s, respectively, an electric potential drop of $20 \%$ in distances $20 \mathrm{~cm}$ from the electrode edges 


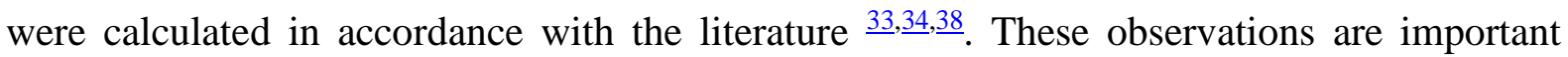
because they offer a plausible explanation of the evolution of the Joule heat phenomenon and provide a firm theoretical basis for the explanation of furnace heating.

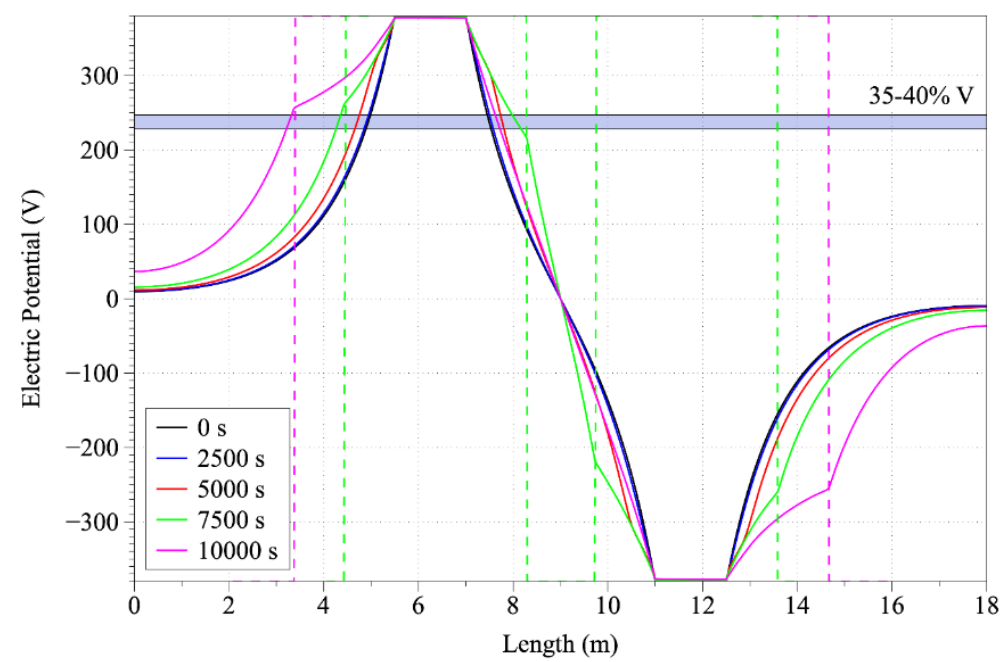

Figure 2. Electric potential distribution across an intercept line from $x_{1}=0$ to $x_{2}=17 \mathrm{~m}$ for constant $\mathrm{y}=1.7 \mathrm{~m}$.

Distribution of electric current density. In Fig.1b a set of current density isosurfaces in the range $0.1-1.5 \cdot 10^{4} \mathrm{~A} / \mathrm{m}^{2}$ at a simulation time of $0.015 \mathrm{~s}$ is presented. In this snapshot, the left electrode was observed to be under a potential of $380 \mathrm{~V}$ while the other two electrodes had a potential of $190 \mathrm{~V}$. The highest current densities observed were located in the slag phase, in the vicinity of the three electrodes. However, a small amount of current densities was also computed to be present in the ferronickel phase, suggesting that a small amount of heat is also produced. Fig.3 depicts the current density pathways in the upper layer of the slag phase (slag-air interaction layer) for several different simulation times. It is evident that the direction of the electric current is following the conventional path, from the electrodes with a positive electric potential to those with a negative potential. 


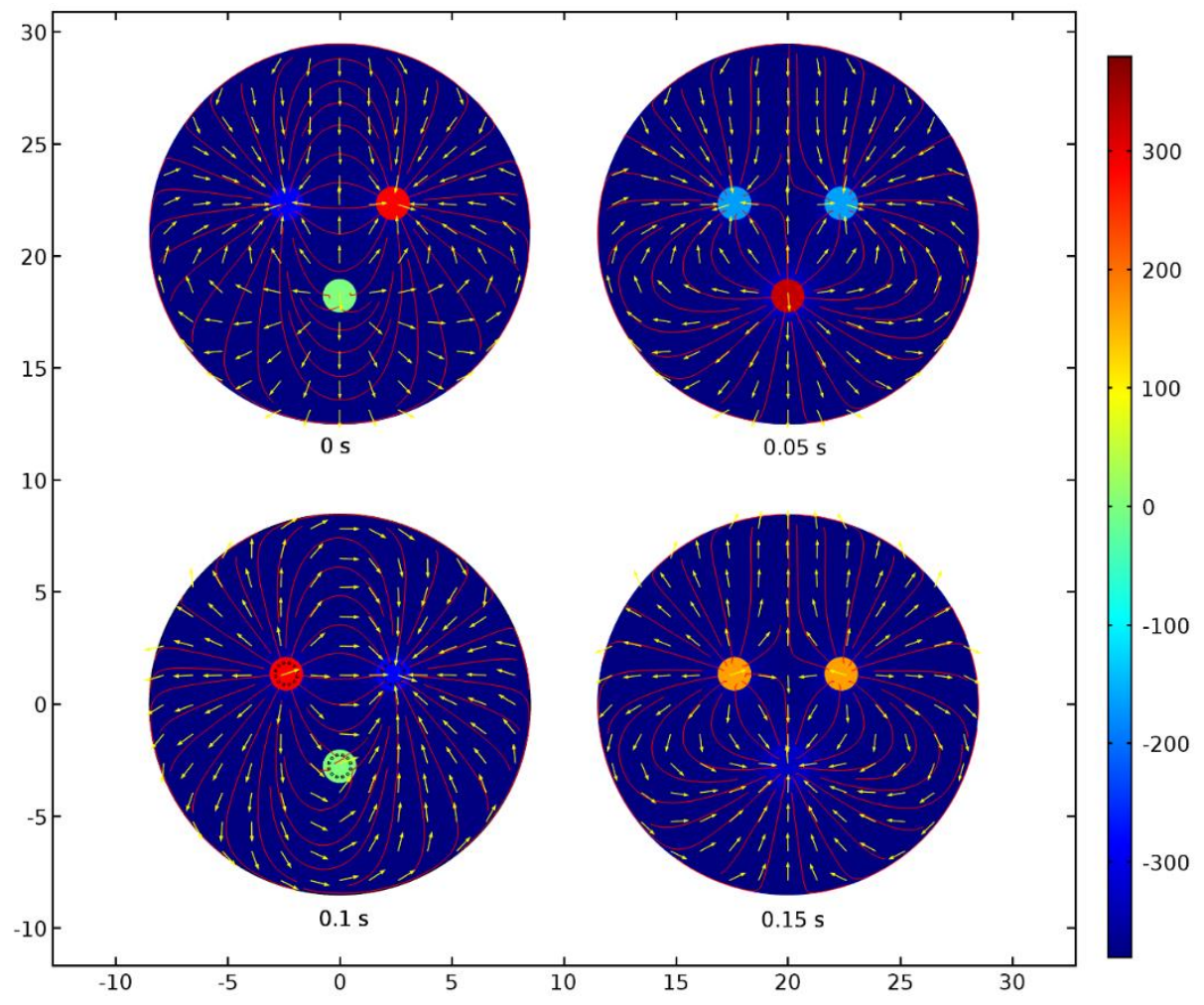

Figure 3. Current density pathways in respect to electrode potential. The conventional pathway from the electrodes with a positive electric potential to those with a negative electric potential is evident.

Distribution of electric power distribution - the Joule phenomenon. Joule heating in the EAF facilitates feed material (calcine) melting and is proportional to the current density (Eq.16). The higher amount of heat is produced in the vicinity of the electrodes resulting in temperature gradient in the bath; due to temperature gradients, the buoyancy phenomenon is increased, leading to more efficient mixing. In Fig. 4, iso-surfaces of the Joule heat at $0.007 \mathrm{~s}$ are portrayed. The higher amount of heat is produced in the slag region close to the electrodes in full accordance with industrial observations where it also observed intense mixing due to higher velocities. 


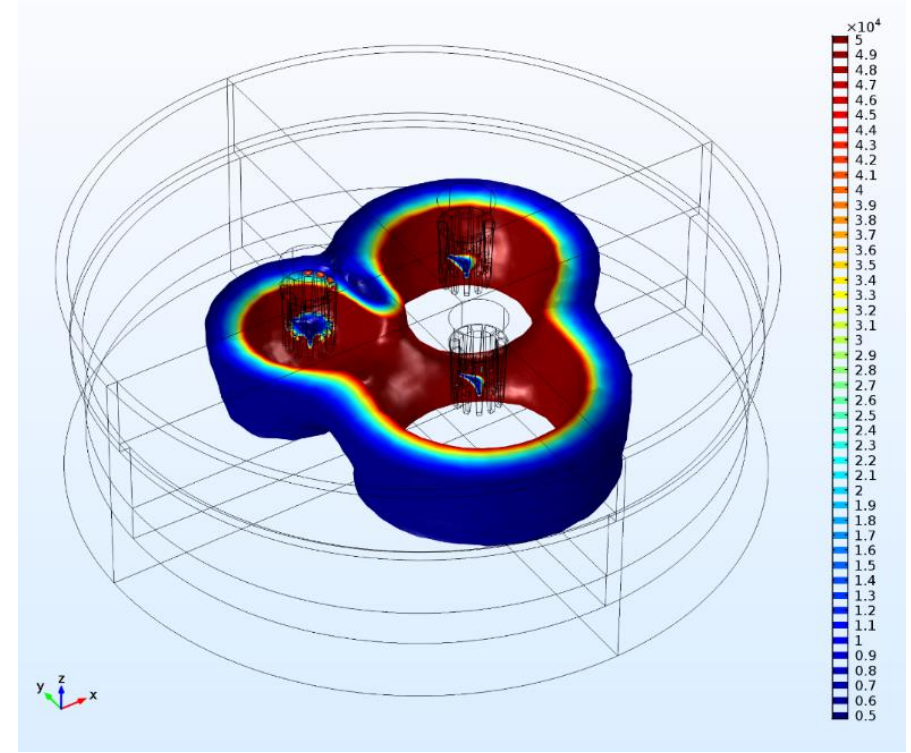

Figure 4. The reductive smelting in EAF is due to the Joule heat. The Joule heat isosurfaces at the time step of $0.007 \mathrm{~s}$ are presented. Due to the slag resistance in the electric current (small electrical conductivity) the maximum amount of heat is produced in the slag region.

Fig. 5 presents the Joule heat with respect to electrode immersion depths of 40 and $60 \mathrm{~cm}$ and with respect to slag electrical conductivity values of 10,30 and $60 \mathrm{~S} / \mathrm{m}$. To analyze the results, a cut line in the $3 \mathrm{D}$ geometry was drawn with coordinates $\mathrm{x}_{1}=0 \mathrm{~m}$ until $\mathrm{x}_{2}=18 \mathrm{~m}$ and constant $\mathrm{y}$ $=1.2 \mathrm{~m}$. From the results it is obvious that the higher values of the slag electrical conductivity lead to higher values of produced Joule heat. Also, the increase of the immersion depth lead to higher amounts of Joule heat in the lower part of the slag region.

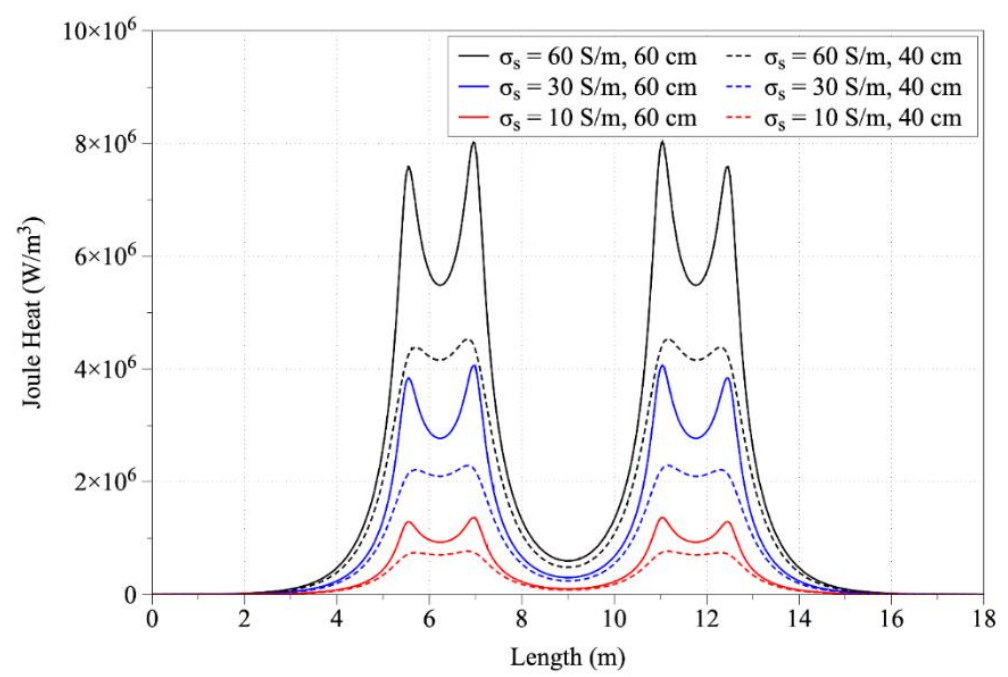

Figure 5. Joule heat distribution as a function of electrode immersion depth and electrical conductivity of the slag. 
Fig. 6 and 7 display the electric potential and temperature distribution for the time steps of 2500, 5000, 7500 and $10000 \mathrm{~s}$, respectively. Due to the temperature dependency of the electrical conductivity of the slag, the electric potential distribution is modified with respect to the time. More specifically, the produced heat increases the temperature which in turn increases the electrical conductivity value which according to Eq.16 leads to the production of higher amount of heat in the next timestep. As shown, the temperature distribution is correlated with the slag electrical conductivity values (Fig. 8). Increasing temperatures lead to correspondingly increasing electrical conductivities and vice versa. As may be observed, at a time step of $10000 \mathrm{~s}$ the temperature in the vicinity of the immersed electrodes is close to $2000 \mathrm{~K}$, in accordance with industrial measurements performed at LARCO S.A.. We performed measurements of the slag temperature via an infrared pyrometer carried out by LARCO S.A., which indicated that temperature varies between $1523-1633 \mathrm{~K}$ at the outlet of the EAF. Also, near the electrodes the temperature varies between 2273-3073 K $\mathrm{K}^{7}$. Hence, initial slag melting occurs in the region between the electrodes, spreading radially thereafter. This phenomenon is due to the current density pathways as shown in Fig. 1 b.

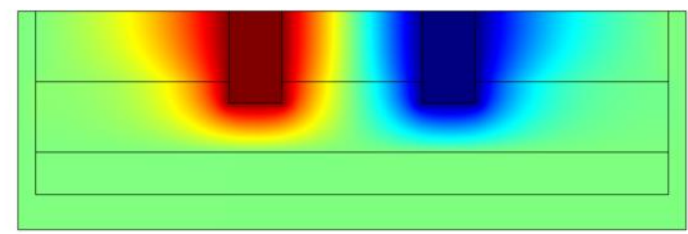

(a)

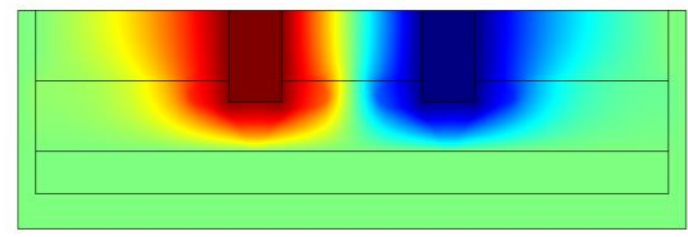

(c)

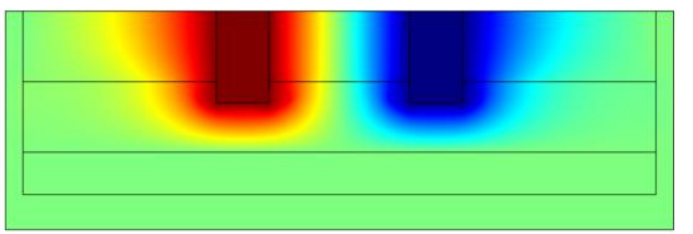

(b)

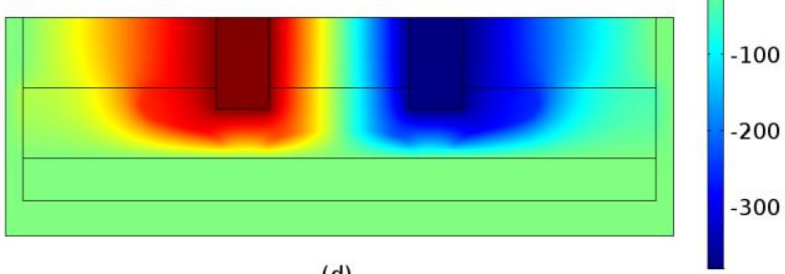

(d)

Figure 6. Potential distribution at times equal to (a) $2500 \mathrm{~s}$, (b) $5000 \mathrm{~s}$, (c) $7500 \mathrm{~s}$ and (d) $10000 \mathrm{~s}$. The maximum absolute values are determined in the vicinity of the electrode tips and monotonically decreases to ground potential $(0 \mathrm{~V})$ values. 


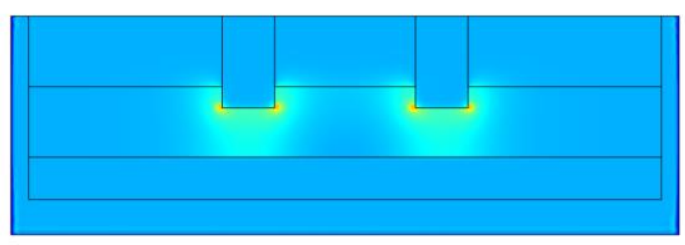

(a)

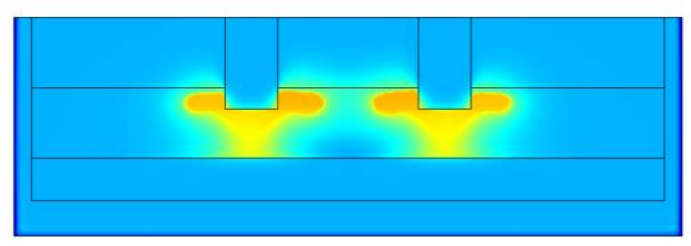

(c)

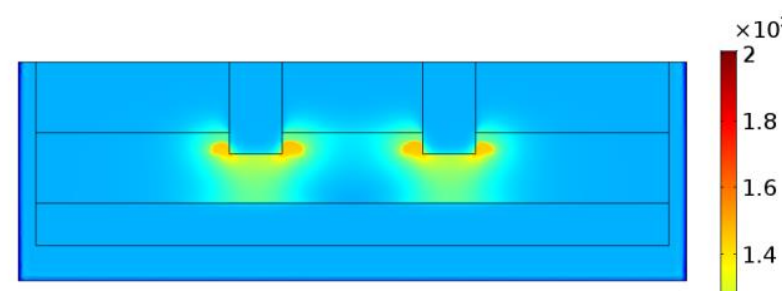

(b)

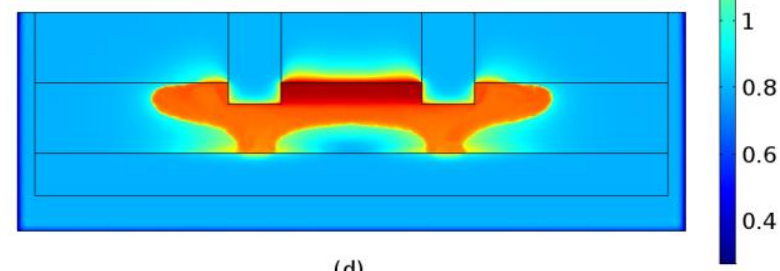

(d)

Figure 7. Temperature distribution in the EAF at times equal to (a) $2500 \mathrm{~s}$, (b) $5000 \mathrm{~s}$, (c) 7500 $\mathrm{s}$ and (d) $10000 \mathrm{~s}$. A direct pathway from the immersed electrode tip to the ferronickel region is observed which can be defined as the submerged arc occurring in the EAFs.

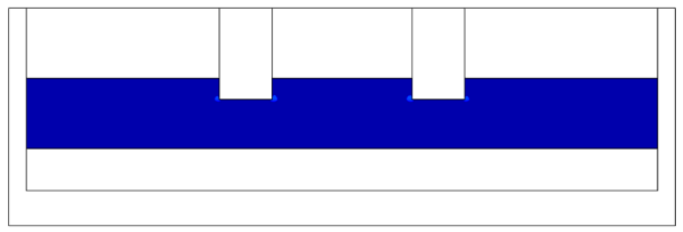

(a)

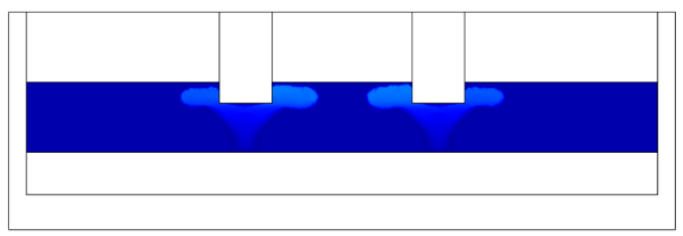

(c)

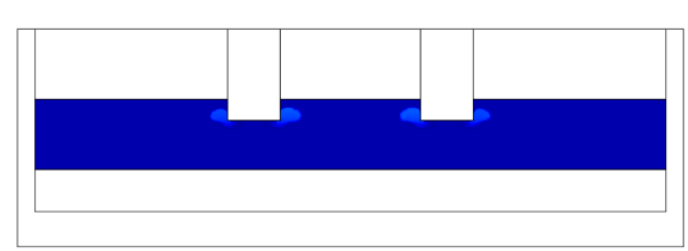

(b)

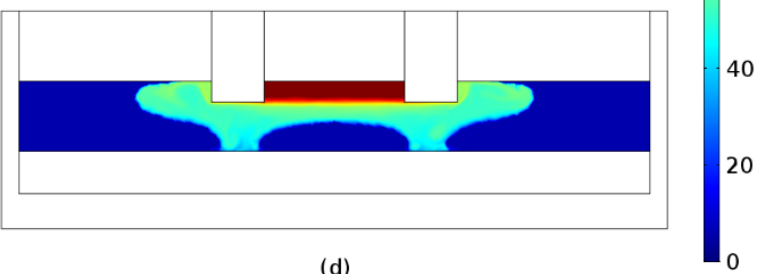

(d)

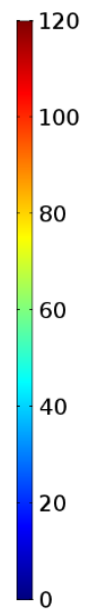

Figure 8. Electrical conductivity of the slag phase at times equal to (a) $2500 \mathrm{~s}$, (b) $5000 \mathrm{~s}$, (c) $7500 \mathrm{~s}$ and (d) $10000 \mathrm{~s}$.

Distribution of slag density and velocity. Due to the variation of temperature in the slag phase, the density varies between $2800 \mathrm{~kg} / \mathrm{m}^{3}$ in the vicinity of the electrodes to $3300 \mathrm{~kg} / \mathrm{m}^{3}$ close to the firebricks (see Fig 9). This variation was observed to lead to stirring of the slag bath due to buoyancy. We could hence deduce that slag melting is favored both from an increase in electrode potential as well as from increasing slag electrical conductivity. The latter is of crucial importance for the optimization of the EAF operation because additives can be used in the feed materials to artificially cause an increase of the electrical conductivity of the slag in a controlled fashion. For example, such additives are $\mathrm{CaO}$ and $\mathrm{MgO}$ which we have 
previously found that it acts by disrupting the alumino-silicate chains ${ }^{4}$. An optimum concentration of these additives can be determined by performing MD parametric analysis using the Buckingham-type transferable interatomic potential ${ }^{\underline{6}}$.

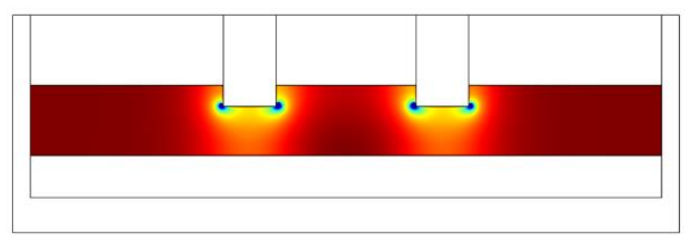

(a)

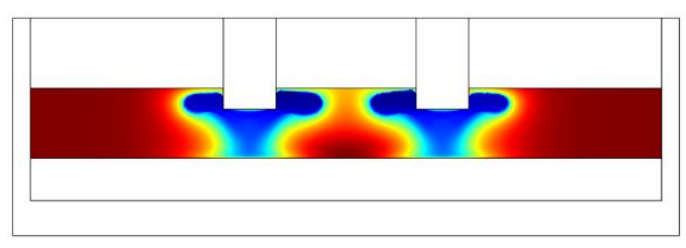

(c)

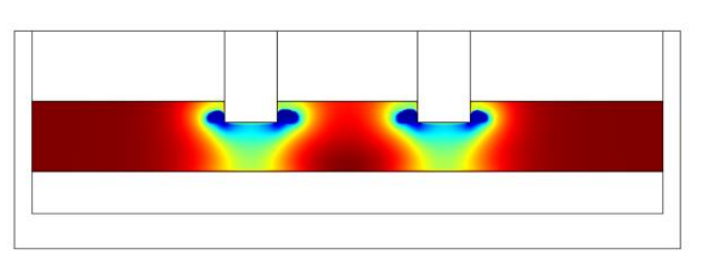

(b)

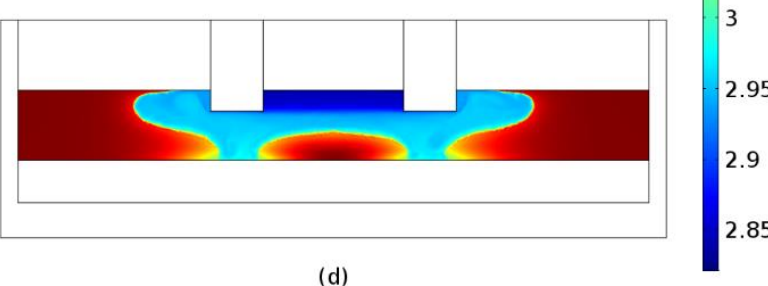

(d)

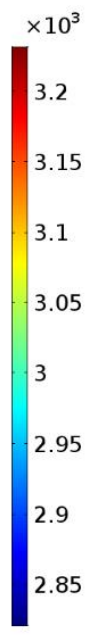

.2
.15
.1
05

(1)

Figure 9. Distribution of slag density with respect to times of (a) $2500 \mathrm{~s}$, (b) $5000 \mathrm{~s}$, (c) 7500 $\mathrm{s}$ and (d) $10000 \mathrm{~s}$. As expected these snapshots are inversely proportional to the temperature distributions (Fig. 7)

The maximum velocities in the vicinity of the electrodes and along the slag solid/liquid

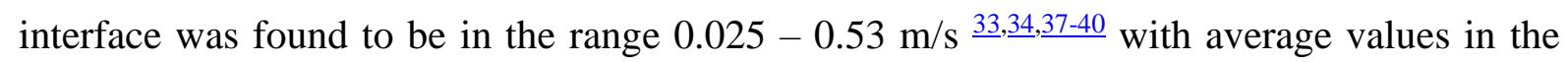
range $0.0001-0.028 \mathrm{~m} / \mathrm{s} \underline{33}, \underline{39}, \underline{41}, \underline{42}$. In Fig. 10, the velocity distribution is presented at times of 2000, 3000, 4000 and $5000 \mathrm{~s}$, respectively. The maximum velocities - equal to $0.1 \mathrm{~m} / \mathrm{s}$ - were detected on the solid/liquid interface of the slag as well as in the regions close to electrode surfaces. Increasing potentials and increasing slag electrical conductivity favor high velocities. For example, an indicative supporting case for this is determined by performing simulations with constant electrical conductivity; an increase in slag electrical conductivity lead to increased velocities. We also observed that this trend is independent of the use of AC current and of use of temperature-dependent electrical conductivities. Three dimensional simulations resulted in markedly lower velocities compared to two dimensional. This result may be attributed to the average Joule heat which is lower in comparison to 2D analysis. Consequently, 3D simulations yield smoother temperature profiles which lead to smaller density deviations and much milder buoyancy effects. However, as can be seen from the dimensionless Péclet number (computed to be excessively larger than unity, 231.3), the slag velocity plays an 
instrumental role in heat transfer-associated phenomena, in a flow which based on the associated Reynolds numbers (0.44) is characteristically laminar.

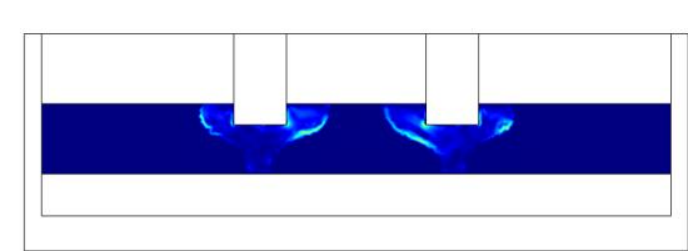

(a)

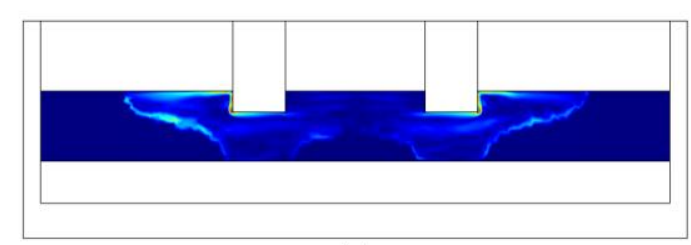

(c)

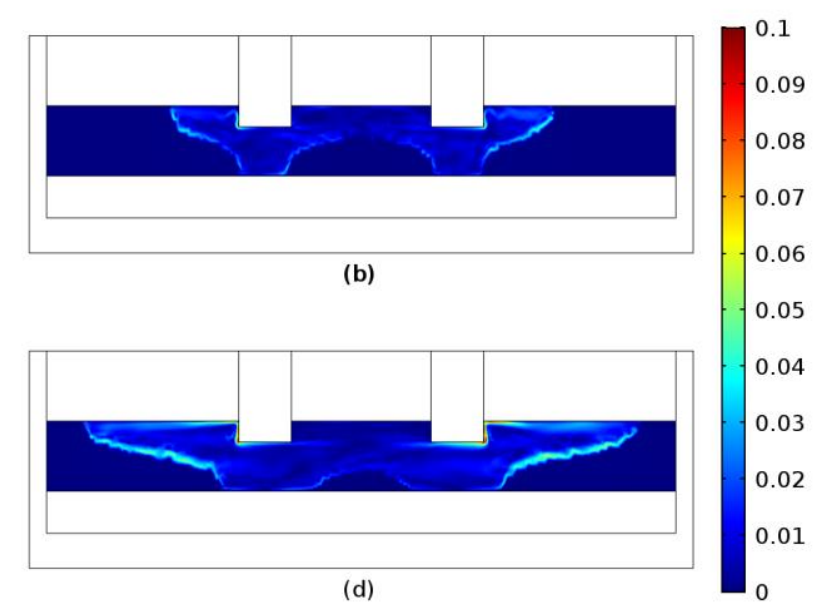

(d)

Figure 10. Velocity distribution in the slag region with respect to times (a) $2000 \mathrm{~s}$, (b) $3000 \mathrm{~s}$, (c) $4000 \mathrm{~s}$ and (d) $5000 \mathrm{~s}$.

Based on analysed with constant electrical conductivity values it was determined that the higher slag electrical conductivity lead to higher Joule heat produced. The average Joule heat produced in the slag region calculated equal to $1905.7 \mathrm{~W} / \mathrm{m}^{3}$ and in the ferronickel equal to $0.27 \mathrm{~W} / \mathrm{m}^{3}$. Increasing electrode immersion depth was determined to lead to higher Joule heat in both the slag and ferronickel phases. This is attributed to the fact that the electric current is transferred through the ferronickel region producing more heat in this region and hence responsible for temperature increase within this phase $\stackrel{43-46}{ }$. Through empirical relationships $\frac{10}{10}$ it was calculated that the thermal conductivity of the slag was in the range of $0.1-1 \mathrm{~W} /(\mathrm{mK})$. Interestingly, any fluctuation of thermal conductivities of this order of magnitude did not appear to affect the outcome of the simulations.

\section{Conclusions}

In the current study a three-dimensional mathematical model describing the transient operation of an electric submerged arc furnace used in the ferronickel production was developed. The use of temperature dependent physical properties leads to instabilities which were results via the use of very small timesteps and fine mesh. One of the key physical properties affecting the operational efficiency which could lead to the reduction of the operational costs is the slag electrical conductivity; higher values lead to the production of higher amounts of Joule heat and consequently favors the smelting procedure. From the nondimensional analysis it was 
revealed that slag flow is unambiguously laminar but with a decisive role in the heat transfer.

The maximum velocities revealed in the vicinity of the three submerged electrodes.

\section{References}

1 Karalis, K., Zografidis, C., Xenidis, A., Tabouris, S. \& Devlin, E. in TMS (The Minerals, Metals \& Materials Society) (2012).

2 Karalis, K., Karkalos, N., Antipas, G. S. E. \& Xenidis, A. in Metal 2015.

3 Karalis, K., Temleitner, L., Antipas, G. S. E., Pusztai, L. \& Xenidis, A. Experimentally constrained atomic order probing of a Si-Al composite glass. Philosophical Magazine, 1-9, doi:10.1080/14786435.2013.863438 (2014).

4 Antipas, G. S. E. et al. A containerless study of short-range order in high-temperature $\mathrm{Fe}-\mathrm{Si}-\mathrm{Al}-\mathrm{Ca}-\mathrm{Mg}-\mathrm{Cr}-\mathrm{Cu}-\mathrm{Ni}$ oxide systems. Journal of Molecular Structure 1019, 151-158, doi:10.1016/j.molstruc.2012.03.056 (2012).

5 Antipas, G., Temleitner, L., Karalis, K., Pusztai, L. \& Xenidis, A. Atomic order and cluster energetics of a $17 \mathrm{wt} \%$ Si-based glass versus the liquid phase. Journal of Physics: Condensed Matter 25, 454206 (2013).

6 Karalis, K. T., Dellis, D., Antipas, G. S. \& Xenidis, A. Bona-fide method for the determination of short range order and transport properties in a ferro-aluminosilicate slag. Sci Rep 6, 30216, doi:10.1038/srep30216 (2016).

7 Karalis, K. T. et al. A CFD analysis of slag properties, electrode shape and immersion depth effects on electric submerged arc furnace heating in ferronickel processing. Applied Mathematical Modelling 40, 9052-9066, doi:10.1016/j.apm.2016.05.045 (2016).

8 Karalis, K., Karkalos, N., Antipas, G. S. E. \& Xenidis, A. Pragmatic analysis of the electric submerged arc furnace continuum. Roy Soc Open Sci 4, doi:10.1098/rsos.170313 (2017).

9 Zhang, S. et al. Relationship between structure and viscosity of $\mathrm{CaO}-\mathrm{SiO} 2-\mathrm{Al} 2 \mathrm{O} 3-$ MgO-TiO 2 slag. Journal of Non-Crystalline Solids 402, 214-222 (2014).

10 Mills, K. The estimation of slag properties. Southern African Pyrometallurgy 7 (2011).

11 Mills, K., Yuan, L. \& Jones, R. Estimating the physical properties of slags. Journal of the Southern African Institute of Mining and Metallurgy 111, 649-658 (2011).

12 GmbH, V. S. Slag Atlas. Vol. 11 (1995).

13 Antipas, G. S., Temleitner, L., Karalis, K., Pusztai, L. \& Xenidis, A. Atomic order and cluster energetics of a $17 \mathrm{wt} \%$ Si-based glass versus the liquid phase. J Phys Condens Matter 25, 454206, doi:10.1088/0953-8984/25/45/454206 (2013).

14 Antipas, G. S. E. et al. A containerless study of short-range order in high-temperature $\mathrm{Fe}-\mathrm{Si}-\mathrm{Al}-\mathrm{Ca}-\mathrm{Mg}-\mathrm{Cr}-\mathrm{Cu}-\mathrm{Ni}$ oxide systems. Journal of Molecular Structure 1019, 151-158, doi:10.1016/j.molstruc.2012.03.056 (2012).

15 Davidson, P. A. An introduction to magnetohydrodynamics. Vol. 25 (Cambridge university press, 2001).

16 Stratton, J. A. Electromagnetic theory. Vol. 33 (John Wiley \& Sons, 2007). 
18 Versteeg, H. K. \& Malalasekera, W. An introduction to computational fluid dynamics: the finite volume method. (Pearson Education, 2007).

19 Voller, V. R. \& Prakash, C. A fixed grid numerical modelling methodology for convection-diffusion mushy region phase-change problems. International Journal of Heat and Mass Transfer 30, 1709-1719 (1987).

20 Viswanath, R. \& Jaluria, Y. A comparison of different solution methodologies for melting and solidification problems in enclosures. Numerical Heat Transfer, Part B Fundamentals 24, 77-105 (1993).

21 Multiphysics, C. (Comsol, 2012).

22 Karalis, K. T., Dellis, D., Antipas, G. S. E. \& Xenidis, A. Bona-fide method for the determination of short range order and transport properties in a ferro-aluminosilicate slag. Scientific reports 6, 30216, doi:10.1038/srep30216 (2016).

23 HO, C. Y. et al. Electrical Resistivity of Ten Selected Binary Alloy Systems. J Phys Chem Ref Data 12, doi:https://doi.org/10.1063/1.555684 (1983).

24 COMSOL-Multiphysics. Reference Guide. (2008).

25 Atlas, S. Verlag Stahleisen GmbH, Düsseldorf. (ISBN 3-514-00457-9, 1995).

26 Ho, C. Y. et al. Electrical resistivity of ten selected binary alloy systems. Journal of physical and chemical reference data 12, 183-322 (1983).

27 Secco, R. Viscosity of the outer core. AGU reference shelf 2, 218-226 (1995).

28 Woolger, C. Invar nickel-iron alloy: 100 years on. Materials world 4, 332-333 (1996).

29 Mills, K. The estimation of slag properties. South African Pyrometallurgy (2011).

30 Kekkonen, M., Oghbasilasie, H. \& Louhenkilpi, S. Viscosity models for molten slags. (2012).

31 Quested, P. et al. Measurement and estimation of thermophysical properties of nickel based superalloys. Materials Science and Technology 25, 154-162 (2009).

32 Faraji, M. \& El Qarnia, H. Numerical study of melting in an enclosure with discrete protruding heat sources. Applied Mathematical Modelling 34, 1258-1275 (2010).

33 Bezuidenhout, J., Eksteen, J. \& Bradshaw, S. Computational fluid dynamic modelling of an electric furnace used in the smelting of PGM containing concentrates. Minerals Engineering 22, 995-1006 (2009).

34 Bezuidenhout, J., Eksteen, J. \& BRADSAW, S. Computational fluid dynamic modelling of a three-phase electric smelting furnace in the platinum smelting process. dimensions 2, 16 (2006).

35 Ritchie, S. \& Eksteen, J. Investigating the effect of slag bath conditions on the existence of multiphase emulsion zones in PGM smelting furnaces using computation fluid dynamics. Minerals Engineering 24, 661-675 (2011).

36 Xia, J. \& Ahokainen, T. Numerical modelling of slag flows in an electric furnace. Scandinavian journal of metallurgy 33, 220-228 (2004).

37 Choudhary, M. \& Szekely, J. The modeling of pool profiles, temperature profiles and velocity fields in ESR systems. Metallurgical Transactions B 11, 439-453 (1980). 
38 Sheng, Y., Irons, G. \& Tisdale, D. Transport phenomena in electric smelting of nickel matte: Part I. electric potential distribution. Metallurgical and materials transactions $B$ 29, 77-83 (1998).

39 Jardy, A., Ablitzer, D. \& Wadier, J. Magnetohydronamic and thermal behavior of electroslag remelting slags. Metallurgical Transactions B 22, 111-120 (1991).

40 Weber, V. et al. A Comprehensive Model of the Electroslag Remelting Process: Description and Validation. Metall Mater Trans B 40, 271-280, doi:10.1007/s11663008-9208-9 (2009).

41 Dilawari, A. \& Szekely, J. A mathematical model of slag and metal flow in the ESR process. Metallurgical Transactions B 8, 227-236 (1977).

42 Arzpeyma, N., Widlund, O., Ersson, M. \& Jonsson, P. Mathematical Modeling of Scrap Melting in an EAF Using Electromagnetic Stirring. Isij Int 53, 48-55, doi:10.2355/isijinternational.53.48 (2013).

43 Jiao, Q. \& Themelis, N. J. Correlation of Geometric Factor for Slag Resistance Electric Furnaces. Metall Trans B 22, 183-192, doi:Doi 10.1007/Bf02652483 (1991).

44 Bertram, L. A., Schunk, P. R., Kempka, S. N., Spadafora, F. \& Minisandram, R. The macroscale simulation of remelting processes. Jom-J Min Met Mat S 50, 18-21, doi:DOI 10.1007/s11837-998-0373-8 (1998).

45 Li, B. K., Wang, B. \& Tsukihashi, F. Modeling of Electromagnetic Field and Liquid Metal Pool Shape in an Electroslag Remelting Process with Two Series-Connected Electrodes. Metall Mater Trans B 45, 1122-1132, doi:10.1007/s11663-013-9996-4 (2014).

46 Ranganathan, S. \& Godiwalla, K. M. Effect of preheat, bed porosity, and charge control on thermal response of submerged arc furnace producing ferrochromium. Ironmak Steelmak 28, 273-278, doi:Doi 10.1179/030192301678145 (2001).

\section{Acknowledgements}

This research was co-financed by the European Regional Development Fund and the Hellenic General Directorate for Research and Technology (action "Cooperation 2011: Partnerships of Production and Research Institutions in Focused Research and Technology Sectors", contract number 11SYN_4_1777, NSRF 2007-2013). The authors also thank Dr. Stelios Tampouris, of LARCO S.A. for providing details on EAF operation.

\section{Author Contributions}

The research was based on the original work by K.K., G.A. and A.X on the ab initio determination of melt slag thermodynamics and kinetics. K.K., N.K. and N.K. laid out the methodology pertaining to CFD. K.K., N.K. and N.K. performed the simulations. K.K. and 
G.A. interpreted the results, and wrote the article. All authors discussed the work at all stages and reviewed the manuscript.

\section{Additional Information}

The authors declare no competing financial interests. 